\title{
Políticas públicas de gestão da Educação do Campo no contexto de reestruturação organizacional do Pronera
}

\author{
Úrsula Adelaide de Lélis ${ }^{1}$, Maria Vieira Silva ${ }^{2}$, Maria Auxiliadora Amaral Silveira Gomes ${ }^{3}$ \\ ${ }^{1}$ Universidade Estadual de Montes Claros - UNIMONTES. Departamento de Educação. Avenida Ruy Braga, \\ Campus Universitário Darcy Ribeiro. Vila Mauriceia. Montes Claros - MG. Brasil. ursulalelis@gmail.com. \\ ${ }^{2}$ Universidade Federal de Uberlândia - UFU. ${ }^{3}$ Universidade Estadual de Montes Claros - UNIMONTES
}

RESUMO. Este texto problematiza a centralidade assumida pelo Instituto Nacional de Colonização e Reforma Agrária (Incra)/Programa Nacional de Educação na Reforma Agrária (Pronera) na gestão da Educação do Campo, secundarizando o papel do Ministério da Educação (MEC). Por meio de um estudo documental, analisa os indícios dessa ação sobre o MEC pelo Incra/Pronera, a partir do Decreto n. 7.352/2010 e dos Manuais de Operações do Programa. Tais reflexões apontam que, desde a criação do Pronera, em 1998, já havia claros sinais de afastamento da gestão da Educação do Campo do MEC, processo fortalecido em 2001, quando o Incra assumiu a gestão do Pronera. Este deslocamento da gestão fragiliza a corporeidade da educação brasileira, que se esvai em políticas desconcentradas e redistribuídas nos demais ministérios do governo. Tal mecanismo pode romper os avanços já alcançados na constituição de um sistema nacional de educação no país, revestindo-a de aspecto e conteúdo focalizador-assistencialista, destituindo-a enquanto direito subjetivo do cidadão brasileiro. Igualmente, evidencia-se que a participação dos movimentos sociais nas atividades de planejamento e acompanhamento das ações do Pronera foi sendo dizimada por meio da reestruturação organizacional do Programa e do Acórdão no 2.653/08 do Tribunal de Contas da União.

Palavras-chave: Políticas Públicas, Gestão, Educação do Campo, Pronera. 


\title{
Public Policies for the Management of Rural Education in the context of organizational restructuring of Pronera
}

\begin{abstract}
This text problematizes the centrality assumed by the National Institute of Colonization and Agrarian Reform (Incra)/National Program for Education in Agrarian Reform (Pronera) in the management of the Rural Education, turning the role of the Ministry of Education (MEC) secondary. This work analyzes through document study the indications of this action on MEC by Incra/Pronera, from the Decree no. 7,352 / 2010 and from the Program Operations Manuals. These reflections indicate that since the creation of Pronera in 1998, there were already clear signs of the withdrawal of MEC from the Field Education management. This process was strengthened in 2001 when Incra took over the management of Pronera. This management change weakens the corporeality of Brazilian education, which is depleted in deconcentrated policies and redistributed in the other government ministries. Such mechanism may jeopardize the achieved results in the constitution of a national education system in the country with aspect and focus-assistentialist content, dismissing it as a subjective right of the Brazilian citizen. It is also evident that the participation of social movements in the activities of planning and follow-up of Pronera's actions was decimated by the organizational restructuring of the Program and Judgment $n^{\circ}$ 2,653 / 08 of the Court of Union accounts.
\end{abstract}

Keywords: Public Policies, Management, Rural Education, Pronera. 


\section{Políticas públicas de gestión de la Educación del Campo en el contexto de reestructuración organizacional del Pronera}

RESUMEN. Este texto problematiza la centralidad asumida por el Instituto Nacional de Colonización y Reforma Agraria (Incra)/Programa Nacional de Educación en la Reforma Agraria (Pronera) en la gestión de la Educación del Campo, poniendo a segundo plano el papel del Ministerio de Educación (MEC). Por medio de un estudio documental, analiza los indicios de esta acción sobre el MEC por el Incra/Pronera, a partir del Decreto $n^{\circ}$. 7.352/2010 y de los Manuales de Operaciones del Programa. Tales reflexiones apuntan que, desde la creación del Pronera, en 1998, ya existían claras señales del apartamiento de la gestión de la Educación del Campo del MEC, proceso fortalecido, en 2001, cuando el Incra asumió la gestión del Pronera. Este desplazamiento de la gestión fragiliza la corporeidad de la educación brasileña, que se desvanece en políticas desconcentradas y redistribuidas en los demás ministerios del gobierno. Tal mecanismo puede romper los avances ya alcanzados en la constitución de un sistema nacional de educación en el país, revistiéndola de aspecto y contenido focalizador-asistencialista, destituyéndola como derecho subjetivo del ciudadano brasileño. Igualmente, se evidencia que la participación de los movimientos sociales en las actividades del planeamiento y acompañamiento de las acciones del Pronera se fue diezmando por medio de la reestructuración organizacional del Programa y del Acuerdo $\mathrm{n}^{\circ}$ 2.653/08 del Tribunal de Cuentas de la Unión.

Palabras clave: Políticas Públicas, Gestión, Educación del Campo, Pronera. 


\section{Introdução}

As políticas públicas de gestão da educação estabelecidas pelo Estado materializam-se via programas e projetos de objetivos e relevos variados, expressando correlações de força, ao mesclarem demandas que emergem no campo das lutas sociais - em especial as que fluem no âmbito do magistério -, com os princípios e determinações da sua face política, no intuito de compor a arquitetura do seu papel de fomentador do capital (Gramsci, 2011; Mészáros, 2011).

Incidindo sobre essa gestão, o Estado imprime aspectos ideológicos, políticos, sociais e econômicos na educação, independentemente de nível ou modalidade de ensino. Tal incidência acentua-se, com relevância, na educação escolarizada, dado que a sua organização desenha-se por leis, portarias, decretos, parâmetros e diretrizes, ao lado de movimentos e determinações que se constituem no cotidiano das escolas, a partir da maneira como se produz e se reproduz a educação escolar (Mészáros, 2011).

Especificamente, a partir dos anos 1990, o Estado brasileiro passou a balizar suas ações em função da estruturação neoliberal da sociedade, impetrando políticas regulatórias que garantissem o controle hegemônico social e político, adotando posições estratégicas a favor da classe proprietária dos meios de produção. Neste campo de disputas, movimentos sociais e sindicais que se colocavam como sujeitos de contestação a tais políticas foram esvaziando-se politicamente e, em alguns casos, adotaram posições fragmentadas por proposições particularistas, afastando-se dos ideais de luta contra-hegemônica. Abriram frente para parcerias, inclusive, com os seus históricos antagonistas.

Tais reconfigurações incidiram significativamente sobre as políticas sociais de governo e de Estado. Dentre estas políticas sociais, na esfera da educação, este texto recorta as que se organizam no âmbito do Programa Nacional de Educação na Reforma Agrária (Pronera), que se destinavam, até o ano de 2010, à formação dos sujeitos de assentamentos agrários, e que hoje abrangem também os do Campo.

Toma-se como eixo de discussão a centralidade assumida pelo Instituto Nacional de Colonização e Reforma Agrária (Incra), vinculado ao Ministério do Desenvolvimento Agrário (MDA) que, por meio do Pronera, congrega a coordenação geral das políticas de formação de professores do Campo, secundarizando o papel do Ministério da Educação, órgão federal que, desde 1930, tem a função 
precípua de gestão das políticas públicas de educação no Brasil, contando com Secretarias e outras unidades destinadas a gerir, dentre outras, a Educação do Campo, como a Secretaria de Educação Continuada, Alfabetização, Diversidade e Inclusão (Secadi).

Quando da sua criação, em 1998, o Pronera invocava o trabalho coletivo com os seus parceiros como premissa básica da sua gestão (Brasil, 2001), mas já apontava indícios da centralização dessa gestão. Contudo, é a partir de 2001, quando o Incra assume a gestão do Programa, que a premissa de gestão coletiva começa a esvair-se, significativamente, e a participação do MEC e dos movimentos sociais e sindicais, nas atividades de planejamento e acompanhamento das ações do Pronera, vai sendo dizimada com o Incra ascendendo ao posto de gestor centralizado da Educação do Campo.

Diante de tais deliberações, este artigo tem por objetivo problematizar a gestão da Educação do Campo pelo Incra/MDA, em detrimento do MEC, a partir da criação do Pronera. Inicia-se essa discussão, apontando algumas reflexões sobre as relações que se estabelecem entre as políticas públicas educacionais e os movimentos sociais e sindicais, bem como sobre as aproximações e distanciamentos existentes entre políticas de Estado e de governo. Em seguida, abre-se para uma análise da centralidade da gestão da Educação do Campo assumida pelo Incra, em detrimento do MEC, e apresenta os indícios de tal deslocamento nos textos do Decreto n. 7.352/2010 (Brasil, 2010) e do Manual de Operações do Pronera (Brasil, 2001; 2004; 2012; 2016a).

\section{Movimentos sociais e sindicais, Estado e políticas públicas}

As lutas que os sujeitos engendram na sociedade refletem formas de resistência às condições materiais e simbólicas presentes na realidade, a favor da constituição real dos seus direitos, enquanto alternativas de superação ao que está posto, por meio de movimentos coletivos.

Pensando sobre esses movimentos, recorre-se a uma das célebres passagens marxistas: “... a humanidade não se propõe nunca senão problemas que ela pode resolver, pois, aprofundando a análise, verse-á sempre que o próprio problema só se apresenta quando as condições materiais para resolvê-lo existem ou estão em vias de existir" (Marx, 2008, p. 48). As reações ante a realidade concreta são novas formas de vida que nascem no interior dos velhos ordenamentos sociais apenas quando prontas às condições orgânicas necessárias para a superação do velho que, em si, gera 
o novo, afirmaria Gramsci (2011), a partir do seu conceito de "revolução passiva". O campo do ocasional, representado pelos esforços incessantes e perseverantes, organiza o antagônico que se esforça para “... demonstrar que já existem as condições necessárias e suficientes para que determinadas tarefas possam e, portanto, devam ser resolvidas historicamente" (Gramsci, 2011, p. 37). O antagônico só se apresenta aos sujeitos pelo processo de esclarecimento - que em si já se constitui como germe no cerne da alienação (Adorno; Horkheimer, 2006) -, quando esses passam a dispor de condições ou précondições materiais - políticas, culturais/teóricas, educacionais - para entendê-lo e superá-lo.

A posse de tais pré-condições desvela-se em crises que se prolongam dando sinais “... que se revelaram (chegaram à maturidade) contradições insanáveis na estrutura e que as forças políticas que atuam positivamente para conservar e defender a própria estrutura se esforçam para saná-las dentro de certos limites e superá-las" (Gramsci, 2011, p. 37). Se dotadas de força pela existência de condições reais profundas, se não forem superficiais e expressarem o terreno necessário à verdadeira mudança, tais contradições geram movimentos realmente orgânicos que sustentam vontades coletivas permanentes, enquanto consciência política coletiva. Não sem embargos, as velhas forças criam os seus próprios mecanismos de resistência. Nesta correlação de forças, elaboram estratégias que, se não podem combater, pelo menos minimizam os efeitos do levante. Não conseguindo resistir, as velhas forças esmeram-se por engendrar silenciosos contramovimentos que, mais adiante, possam lhes restaurar, pelo menos em parte, o que foi perdido.

A realidade é um equilíbrio de forças em contínuo movimento e mudança de equilíbrio; portanto, o movimento nunca cessa. No seu interior, há sempre o germe da transformação, alimentado pela própria existência do seu antagônico. Do movimento de tais forças, pode-se constituir uma nova realidade.

São os movimentos sociais e sindicais que, tradicionalmente, encarnam a representação do antagônico na sociedade, mesmo que, nem sempre, se constituam como orgânicos. É a situação e o sentimento de não pertencimento ao circuito dos direitos que levam os sujeitos a se organizarem em lutas e movimentos. É a busca pela efetivação da cidadania plena que os move. Ela é o mote perseguido, entendida como realização dos direitos sociais, políticos e civis existentes e dos que possam vir a constituir-se legalmente. 
Expressando as lutas que os sujeitos engendram no âmbito do Estado, os movimentos sociais são formas de resistência às condições materiais $\mathrm{e}$ simbólicas postas, por meio das quais produzem suas vidas enquanto alternativas de superação da realidade. São processos tecidos, constituídos no espaço da sociedade civil como resultado das contradições que nela se estabelecem pelas ações dos homens.

Os movimentos sindicais, mesmo representando categorias específicas do mundo do trabalho, em sua formação ontológica, também se constituem como mecanismos de luta, defesa e reivindicação dos direitos de tais categorias. São eles que, juntamente com os movimentos sociais, encarnam as vontades coletivas, apresentando-se como respostas aos antagonismos políticos, econômicos e sociais.

Contudo, as transformações ocorridas no seio dos movimentos sociais e sindicais - como consequência da reestruturação neoliberal da sociedade, nos anos 1990 - ressignificaram a sua dimensão contra-hegemônica, individualizando seus horizontes de luta em prol de causas que atendem, de maneira aligeirada e pontual, a um grupo ou a pequenos grupos, perdendo a noção de totalidade da sua classe: a trabalhadora.
Mantendo-se como "classe em si" dimensão econômico-corporativa - , bem como "classe para si" - dimensão políticoinstitucional, esses movimentos se não abandonaram, atenuaram sua característica primeira de "classe para além de si" dimensão contra-hegemônica, na perspectiva do gênero humano.

A partir do momento em que se fragmentaram em movimentos menores, delimitados ideológica e socialmente, lutando apenas pelo direito imediato de determinados grupos usufruírem de bens e equipamentos coletivos, direta e indiretamente, os movimentos, especificamente os sociais, perderam sua característica de classe, sua força, sua capacidade de mobilização e de transformação real do cotidiano. Ao defenderem causas particularistas, como se, por exemplo, a construção de uma creche, por si só, resolvesse todos os problemas da classe que vive do trabalho, ignorando que as questões que envolvem as condições de vida e de trabalho são muito mais profundas, tais movimentos tornam-se apenas "movimentos em si" e "para si". Neste caso, apresentam-se como "novos" movimentos sociais, uma estratégia que se ocupa de enfraquecer qualquer tentativa de mobilização social sólida e capaz de arregimentar mudanças estruturais ${ }^{\text {ii }}$. 
Essa estratégia articulada em torno do esvaziamento do caráter político dos movimentos sociais e sindicais, da fragilização de seus ideais, da retirada da centralidade da luta de classes de seu cerne caracteriza-se como um mecanismo explícito de contra-regulação engendrado pelo sistema de capital, no qual o Estado é o seu grande aliado, para enfraquecer as lutas e tornar mais fácil a repressão ou o atendimento fatiado dos direitos.

O Estado, com suas estruturas legal, política e ideológica, desenvolve relações de complementaridade e de servitude ao sistema de capital, a fim de assegurar, para a superação das suas crises, as condições gerais de produção, expansão e acumulação do capital. Assim, ele é um componente essencial para o funcionamento desse sistema, parte integrante da sua base material, a sua dimensão política, sem, contudo, ser subordinado a ele, uma vez que “... o capital é o seu próprio sistema de comando" (Mészáros, 2011, p. 124).

No que tange aos movimentos sociais e aos sindicais, com a consumação de tal estratagema, questões pertinentes à relação capital/trabalho são afastadas do centro das lutas e adensadas sutilmente em favor da composição de uma sociedade fundamentada nos princípios do capital, destituindo esses movimentos de sua capacidade de arregimentar a mudança social, atingindo a representação, a constituição e a essência desses movimentos, na íntegra.

Essa perda de força e de capacidade de mobilização em torno de lutas orgânicas colabora para o adensamento dos movimentos e enfraquece a sua participação na propulsão de políticas públicas tanto de governo quanto de Estado.

As políticas públicas representam o resultado das correlações de força na sociedade, na qual o equilíbrio está sempre por vir. Expressam o quê da demanda material concreta conseguiu ser constituído legalmente, para voltar a essa mesma realidade e produzir as mudanças pelas quais se lutou. Se tais políticas não conseguem girar esse ciclo, a luta não cessa, e se refaz, às vezes, em outras frentes. Portanto, a existência de ordenamentos jurídicos não garante a efetividade do atendimento ao que os demandou, o que, contudo, não secundariza a importância da existência de um ordenamento jurídico de Estado ou de governo.

O povo de um Estado é o titular do poder e se faz representar, transitoriamente, por um governo. Constitucionalmente, uma política pública deve proteger e promover os direitos 
reconhecidos desse povo; caso contrário, torna-se ilegal. No campo do Direito, uma política pública é considerada como “... atividade estatal de elaboração, planejamento, execução e financiamento de ações voltadas à consolidação do Estado Democrático de Direito e à promoção e proteção dos direitos humanos", e o Estado - no sentido restrito de sociedade política/governo - é sempre o sujeito ativo dotado de competência constitucional para realizá-las (Aith, 2006, p. 232). Na prática, não só o flanco político desse Estado tem realizado ações de políticas públicas. A sua face civil também o tem feito. Neste sentido, políticas de Estado diferenciam-se de políticas de governo pelos objetivos e pelas formas de elaboração, planejamento, execução e financiamento (Aith, 2006).

As políticas de Estado estão ligadas a finalidades essenciais, à organização, estrutura e desenvolvimento do Estado, enquanto as de governo primam pela pontualidade, flexibilização mais acentuada (discricionariedade governamental) e maior especificidade nos objetivos. Estas estariam a serviço das primeiras, com a função de implementá-las e potencializá-las. Quanto à forma de elaboração, planejamento e execução, uma política de Estado tem caráter mais permanente. Não pode ter quebra de continuidade, e deve ser realizada apenas por governos, podendo contar com a participação de instituições da Sociedade Civil apenas de maneira complementar, subsidiária, mas sempre subordinada ao Estado. Já as de governo podem ter a sua execução delegada ou terceirizada até mesmo integralmente; têm caráter transitório, e podem variar de governo para governo (Aith, 2006).

Em relação ao financiamento, as políticas de Estado devem ser financiadas exclusivamente com recursos públicos; ao contrário das de governo, que podem contar com recursos privados (Aith, 2006).

Ao perderam força, capacidade de mobilização, poder de luta coletiva e representatividade de classe, os movimentos sociais e sindicais também perdem o poder de determinação sobre a criação, implantação e implementação de políticas públicas, sejam elas de governo ou de Estado.

\section{Políticas públicas de Educação do Campo: a quem cabe esta gestão?}

Recortando as lutas dos movimentos sociais para o espaço do Campo, pode-se afirmar que elas se estabelecem a partir de uma realidade que transcreve cenários de abandono, precariedade e descaso na História da educação, no Brasil. Cenários sempre secundarizados e pospostos ao paradigma da escola urbana, tomada como 
protótipo de escola e sujeitos de direito (Arroyo, 2007). Entretanto, é esta concretude que gera as condições para a realidade dissolver-se, levando os povos do Campo a se organizarem na busca de legitimação das suas necessidades históricas, na disputa pela hegemonia ideológica marcada numa dinâmica social que consubstancia as políticas públicas (Antonio \& Martins, 2009). Essa exclusão reflete a pouca ou nenhuma visibilidade que tais necessidades sempre tiveram nos textos e nas práticas das políticas públicas, bem como a expressão das suas causas resultarem em "pequenas" políticas de governo e nem sempre de Estado.

O lugar marginal que a Educação do Campo ocupou, e ainda ocupa, nas políticas públicas educacionais nega a sua população o acesso à educação como direito constitucional fundante da cidadania, deixando essa população à mercê das orientações dos grupos agrários, dos senhores proprietários de fazendas e latifúndios, a quem coube, historicamente, organizar a educação nas "escolinhas das fazendas" (Arroyo, 2007; Freitas, 2008; Antonio \& Martins, 2009).

Tal realidade levou à centralidade histórica, nos movimentos sociais do Campo, a luta pela educação ao lado da luta pela reforma agrária, por meio da arregimentação de vários encaminhamentos, dos quais se destaca a realização do I Encontro Nacional de Educação na Reforma Agrária (Enera), ocorrido em julho de 1997. Esse encontro resultou na criação do Pronera, em 16 de abril de 1998, por meio da Portaria $n^{\circ}$ 10/98 (Brasil, 1998), vinculado, naquele momento, ao então Ministério Extraordinário da Política Fundiária, e, hoje, ao Ministério do Desenvolvimento Agrário, com participação dos movimentos sociais do Campo e de universidades brasileiras públicas e comunitárias. A partir de 2001, o Programa foi incorporado ao Incra.

Constituído inicialmente como política de governo, o Pronera ascendeu ao status de política de Estado em 04 de novembro de 2010, pelo Decreto $\mathrm{n}^{\circ}$. 7.352/2010 (Brasil, 2010), ampliando o seu atendimento às populações do Campo e ratificando, de maneira explícita, a sua gestão ao Incra.

$\mathrm{Na}$ época de sua criação, o Pronera elegeu, inicialmente, a Educação de Jovens e Adultos como modalidade prioritária de atendimento; e tinha como metas a alfabetização dos assentados, a escolarização dos monitores, a formação continuada de educadores e a formação de técnicos para a produção agropecuária, e de gestores para o empreendimento rural. Seu objetivo envolvia, também, a saúde e a 
comunicação, organizando, produzindo e editando materiais didático-pedagógicos para o Programa, a fim de "... fortalecer a educação nas áreas de Reforma Agrária estimulando, propondo, criando, desenvolvendo e coordenando projetos educacionais, utilizando metodologias voltadas para a especificidade do campo, tendo em vista contribuir para a promoção do desenvolvimento sustentável” (Brasil, 2004, p.15).

Marcadamente compensatório, mesmo com as mudanças impetradas pelo Decreto $\mathrm{n}^{\circ}$. 7.352/2010, o Pronera evidencia, na sua legislação, o traço do assistencialismo recorrente em muitas políticas públicas sociais brasileiras, sustentando o antagonismo de, mesmo se constituindo agora em política de Estado, denominar os cidadãos como "beneficiários" e não como sujeitos de direito. Não menos ambíguo é manter uma política de educação sob a coordenação do MDA e com "apoio técnico e financeiro" do MEC (art. $4^{\circ}$ e $9^{\circ}$ ) (Decreto $\mathrm{n}^{\mathrm{o}}$ 7.352/2010). Ao MEC cabe, a partir desse Decreto, um papel secundário, como coadjuvante, que pode “... realizar parcerias com outros órgãos e entidades da administração pública para o desenvolvimento de ações conjuntas, e para apoiar programas e outras iniciativas no interesse da educação do campo, observadas as diretrizes fixadas neste Decreto" (Brasil, 2010).

O Incra, criado pela Lei $\mathrm{n}^{\circ} 1.110$, de 9 de julho de 1970 (Brasil, 1970), é uma autarquia vinculada ao MDA, que apresenta, em sua Estrutura Regimental, as competências dos seus órgãos e unidades. No que concerne às competências das suas Secretarias, não há nenhum registro de suas atribuições específicas a qualquer processo formal de educação. Há, apenas, na referência às Secretarias de Reordenamento Agrário e da Agricultura Familiar, alusão à tarefa de apoiar e/ou participar, e/ou promover algumas ações e programas de pesquisa que visem à profissionalização dos agricultores familiares.

No que diz respeito ao Incra (Decreto $n^{\circ}$ 6.812/2009), a quarta diretriz desse Instituto determina que a implementação da reforma agrária buscará a qualificação dos assentamentos rurais, mediante ações diversas, dentre as quais se encontra a articulação com políticas públicas, inclusive as de educação. Vale ressaltar que o texto enfatiza a articulação do Incra com outras políticas já estabelecidas; ou seja, que este deva se colocar como parceiro, auxiliar de outras políticas públicas já implantadas, e não tornar-se o propositor direto de novas políticas de educação. 
Contudo, uma nova vertente adotada por esse Instituto substitui essa perspectiva de articulação, capitalizando para si as políticas públicas de Educação do Campo, como se pode constatar em várias passagens da sua Estrutura Regimental e Regimento Interno, aprovados pelo Decreto $n^{\circ}$. 6.812, de 3 de abril de 2009 (Brasil, 2009a). No item IV, do art. 17, do capítulo $\mathrm{V}$, deste documento, que trata das competências dos Órgãos, determina-se que à Diretoria de Desenvolvimento de Projetos de Assentamento compete “... desenvolver, acompanhar e supervisionar projetos relativos à educação do campo e cidadania” (Brasil, 2009a, p. 8).

Não sem embargos, o Regimento Interno do Incra, aprovado pela Portaria $n^{\circ}$. 20, de 08 de Abril de 2009 (Brasil, 2009b, p. 19), estabelece, na seção II, do seu art. $2^{\circ}$, que esse tem como atividades principais, dentre outras, “... proporcionar a educação formal em todos os níveis, ensino básico, profissionalizante de nível médio e superior, para o público da reforma agrária, visando a promoção da igualdade no meio rural", contando, também, com uma Coordenação Geral de Educação do Campo e Cidadania, e uma Divisão de Educação do Campo, específicas para esse fim, cabendo à primeira definir a gestão política e pedagógica do Pronera, ou de outro que venha a substituí-lo. Tal propósito foi ratificado no atual Regimento Interno do Instituto (Brasil, 2017), aprovado em $30 \mathrm{de}$ janeiro de 2017.

Conforme o Decreto n. 7.352/2010, o Pronera, enquanto política pública, objetiva:

art. 12: I - oferecer educação formal aos jovens e adultos beneficiários do Plano Nacional de Reforma Agrária PNRA, em todos os níveis de ensino; II - melhorar as condições do acesso à educação do público do PNRA; e III - proporcionar melhorias no desenvolvimento dos assentamentos rurais por meio da qualificação do público do PNRA e dos profissionais que desenvolvem atividades educacionais e técnicas nos assentamentos (Brasil, 2010).

Nesse contexto, por que desenvolver ações formais de educação fora do âmbito do Ministério da Educação? Ou, por que o Pronera não se compõe em ação conjunta entre MEC e MDA/Incra?

Santos (2010, p. 2) analisa como positivo o fato de, mesmo estruturando-se como uma política de Educação do Campo, o Pronera preservar a

... sua especificidade de política pública de educação vinculada à Reforma Agrária. Isso é uma inovação importante: um governo reconhecer que há processos educativos formais que não necessariamente passam pelo sistema educacional, pelo regime de colaboração, mas passam por outras instâncias do Estado que têm 
condições diferenciadas de gestão, porque lidam no cotidiano com questões que são do mundo dos camponeses, que nem sempre as políticas universais são capazes de absorver. Oxalá avancemos no próximo período para que as políticas universais tornem-se cada vez mais abertas a tais inovações. Do meu ponto de vista, esta é uma condição fundamental para melhorar os índices de escolaridade no campo. Que o sistema educacional se abra para novas formas de organizar os processos educativos escolares, fora do desenho quadrado das escolas que conhecemos.

Na sua análise, Santos (2010) afirma que o MEC não teria condições de lidar com as questões da Educação do Campo, desconsiderando que, no seu corpo organizacional, há Secretarias para atendimentos especializados, como é o caso da Secadi, criada em julho de 2004, que trata de temas ligados à Educação do Campo, Alfabetização e Educação de Jovens e Adultos, Educação Ambiental, Educação em Direitos Humanos, Educação Especial, Indígena, Quilombola e para as Relações Étnico-raciais.

Desconsidera, também, que as modalidades de educação, sobre as quais o Pronera tem atuado com maior incidência, localizam-se no âmbito do sistema educacional formal, como é o caso dos cursos superiores. Isso coloca em xeque questões não apenas pedagógicas, mas também políticas e econômicas, como é o caso do financiamento.
No Brasil, o histórico do financiamento da educação é marcado por desafios que perpassam pela articulação do regime de colaboração entre os entes federados, pelo cumprimento do piso salarial de professores, pelo cálculo real do custo/aluno e pelas desigualdades intraestaduais.

A educação é a única política social brasileira com recursos vinculados desde 1934, e a alocação de recursos federais neste setor cresceu, no período de 2004 a 2014, 130\%, segundo dados do Boletim Legislativo $\mathrm{n}^{\circ}$. 26/2015, passando de $4 \%$ da receita líquida do Tesouro, em 2004, para 9,3\% em 2014, ocupando o $3^{\circ}$ lugar de maior investimento do Tesouro, e “... somente nos três últimos anos da série (2012-2014) a União gastou $\mathrm{R} \$ \quad 43,1$ bilhões acima do limite mínimo (uma média de $\mathrm{R} \$ 14,4$ bilhões a mais por ano)..." (Mendes, 2015, p. 2).

$\mathrm{O}$ orçamento da educação, que em 2014 chegou a 94.201 bilhões (Mendes, 2015), coloca esse setor no campo das disputas pelo financiamento público, sobre o qual dois aspectos merecem destaque: primeiro, a concorrência dentro do próprio MEC sobre a alocação desses recursos por grupo de natureza da despesa. Segundo, perdendo a gestão da Educação do Campo, dado que esta passa a disputar os recursos do Ministério do Desenvolvimento 
Agrário, os valores seriam destinados a outras áreas no Ministério da Educação. Por outro lado, tal repasse de funções pode, futuramente, incidir sobre o orçamento do próprio MEC, que, ao ter sua ação reduzida, dará margem à revisão do seu orçamento, inclusive de forma jurídica. Este é um risco que o MEC está tentando resolver, mantendo algumas ações para a Educação do Campo dentro da Secadi.

Parece emblemática a negativa de um trabalho conjunto, integrado entre MDA/Incra e MEC para o Pronera, com centralização da gestão no Incra, mesmo após mudança do seu patamar para política de Estado e ampliação da área de atuação, incidindo agora sobre toda a Educação do Campo.

Por outro lado, há que se ressaltar que o MEC, via Secadi, só administra a rede federal de educação e desenvolve, atualmente, por meio da Diretoria de Políticas de Educação do Campo, Indígena e para as Relações Étnico-raciais, quatro programas. Destes, somente dois contemplam os povos do Campo: o Programa Nacional de Educação do Campo (Pronacampo) ${ }^{\text {iii }}$ e o Programa de Educação Tutorial (PET) Conexões de Saberes $^{\text {iv }}$. É, portanto, num vácuo de políticas públicas do MEC que o Incra/MDA ganha ascendência na gestão da Educação do Campo.

Nesse contexto, há que se ressaltar, também, os dados da atuação do Pronera, apresentados pela II Pesquisa Nacional sobre a Educação na Reforma Agrária (Pnera) (Ipea, 2015). Eles representam a ampliação da gestão do Incra sobre a educação, em detrimento do MEC.

Tabela 1. Alunos Atendidos pelo Pronera, no Período de 1998 a 2011.

\begin{tabular}{l|l|c|c}
\hline \multicolumn{1}{c|}{$\mathbf{N}^{\mathbf{0}}$} & \multicolumn{1}{|c}{ Modalidades } & Ingressantes & Concluintes \\
\hline 1 & Educação de Jovens e Adultos & 154.192 & 75.280 \\
2 & Ensino Médio & 7.379 & 4.900 \\
3 & Ensino Superior - graduação & 2.635 & 2.188 \\
4 & Ensino Superior - pós-graduação & 373 & 261 \\
5 & Residência & 315 & 266 \\
& Total de Alunos & 164.894 & 82.895 \\
\hline
\end{tabular}

Fonte: Ipea (2015).

No período de 1998 a 2011, foram realizados 320 cursos em 880 municípios brasileiros, em parceria com 247 instituições parceiras. A maioria dos alunos, 76.633, era de assentamentos agrários -, e 12.876 professores atuaram nos cursos (Ipea, 2015). Quanto ao financiamento, o custo aluno/ano no Pronera variou, em 2015, entre $\mathrm{R} \$$ $2.700,00$ (alfabetização) e R $8.300,00$ 
(pós-graduação) (Brasil, 2015). No Ministério da Educação, a média do custo/aluno, no mesmo ano, foi de R\$ 2.545,31, na Educação Básica, ou seja, $5,72 \%$ a menos. Já um aluno no ensino superior teve um custo maior, via MEC, do que no Pronera: R \$ 8.654,05 (Portal Brasil, 2010).

No que tange à gritante diferença entre ingressantes e concluintes em tais cursos, é preciso ponderar, a partir de Silva e Araújo (2017, p. 36), que o debate sobre a evasão no Brasil deve ser entendido como abandono escolar e que, ao discutir esse assunto “... é necessário ter como eixo a compreensão de suas dimensionalidades dentro da educação brasileira, pois as causas se apresentam como desagregadoras da educação em todas as regiões do país". Portanto, a leitura os dados da Tabela 1, mesmo considerando-se o altíssimo índice de $50 \%$ de não concluintes dos cursos, exige a consideração da importância política, social, cultural e educacional do Pronera como um dos programas educacionais de maior abrangência localizada (antes para os assentamentos agrários e, a partir de 2010, para todo o Campo) no Brasil. Deve-se, também, reconhecer que tais percentuais acentuam a problemática apresentada por este texto: por que as ações para a Educação do Campo encontram-se sobre gestão do Incra e não do MEC? Quais as consequências deste deslocamento para a Educação do Campo? E ainda: o Incra está capacitado para lidar com os temas referentes à educação? Os dados evidenciam, também, o alto índice da demanda de Educação de Jovens e Adultos, nos assentamentos de reforma agrária e no Campo, e que não estão concluindo a escolarização básica e superior, colocando em xeque a atuação do Incra, na oferta de educação.

Em 2004, o Pronera estabelecia que a coordenação dos seus projetos deveria estar sob a responsabilidade de um professor da instituição de ensino superior, que teria como tarefa a sua formulação, implantação, acompanhamento, controle técnico-operacional e sua avaliação (Brasil, 2004). Tal encaminhamento foi revogado pelo Decreto $\mathrm{n}^{\mathrm{o}} 7.352 / 2010$, que retirou de cena as universidades $-\mathrm{e}$ consequentemente afastou o MEC ainda mais do processo -, bem como anulou o papel dos movimentos sociais, ao dispor como atribuições do Incra:

... coordenar e supervisionar os projetos executados no âmbito do Programa; II - definir procedimentos e produzir manuais técnicos para as atividades relacionadas ao Programa, aprovando-os em atos próprios no âmbito de sua competência ou propondo atos normativos da competência do Ministro de Estado do Desenvolvimento Agrário; e III coordenar a Comissão Pedagógica 
Nacional de que trata o art. 17. (Brasil, 2010).

Aos movimentos sociais cabia, no ano de 2001,

\begin{abstract}
... mobilizar jovens $\mathrm{e}$ adultos moradores de Projetos de Assentamento de Reforma Agrária para a identificação das demandas; identificar, em conjunto com os demais parceiros, os Projetos de Assentamento que serão atendidos; participar do acompanhamento pedagógico dos projetos; articular, em conjunto com a Secretaria Municipal de Educação e o INCRA, a infraestrutura necessária ao bom funcionamento das salas de aulas; acompanhar o trabalho dos monitores assegurando frequência às aulas; acompanhar a aplicação dos recursos e execução do Plano de Trabalho e do Projeto (Brasil, 2001, p. 22).
\end{abstract}

Os movimentos sociais assumiram, nesse momento, um papel de co-gestores dos projetos para a educação escolar nos assentamentos, abarcando funções administrativas, financeiras e pedagógicas. O Movimento Sindical de Trabalhadores Rurais (MSTR) não foi citado no Manual de 2001 (Brasil, 2001). Ele aparece somente em 2004 (Brasil, 2004, p. 20-21), como parceiro, ao lado dos movimentos sociais, dividindo com estes atribuições que ampliavam as suas parcerias com o Pronera:

... mobilizar jovens e adultos moradores das áreas de Reforma Agrária para identificação das demandas; identificar, em conjunto com os demais parceiros, as áreas de Reforma Agrária que participarão dos projetos; participar da elaboração e do acompanhamento durante a execução dos projetos educacionais; buscar, em conjunto com as instituições públicas de ensino, governos estaduais e municipais e o INCRA, a infraestrutura necessária ao funcionamento do programa nas Áreas de Reforma Agrária; acompanhar, em conjunto com os demais parceiros, todo o processo pedagógico desenvolvido pelos(as) educadores(as) e coordenadores(as) locais quanto à adequação curricular, metodologias, formas de participação, entre outros; participar da seleção e capacitação $\operatorname{dos}($ as) educadores(as) das áreas de Reforma Agrária; discutir, acompanhar e avaliar em conjunto com os demais parceiros a aplicação dos recursos e execução do Plano de Trabalho e do Projeto.

Pode-se observar que as atribuições dos movimentos no Pronera cresceram significativamente a partir de 2004, demandando-lhes mais poder de decisões e comando. Suas atribuições ampliaram-se no que tange a questões ligadas diretamente ao currículo: ganharam mais autonomia para interferir no processo pedagógico; ampliou-se sua responsabilidade sobre a infraestrutura necessária ao bom funcionamento das salas de aulas do programa nas áreas de reforma agrária; passaram a participar da seleção e capacitação dos(as) educadores(as) das áreas de reforma agrária; passaram a discutir, acompanhar e avaliar, em conjunto com os demais parceiros, a 
aplicação dos recursos e execução do plano de trabalho e dos projetos.

A participação dos movimentos sociais na Educação do Campo foi um grande avanço na democratização da educação, promovendo um marco político, institucional e cultural para os povos do Campo. Significava uma nascente política no chão da Educação Popular, rompendo com uma tradição vertical e centralizadora da política pública. Com o Pronera, o povo do Campo colocava-se como protagonista para discutir e decidir seus projetos de educação. Entretanto, esse Programa criado pela mobilização da face civil do Estado começou a perder características políticas e sociais sobre as quais foi fundado. Diante da “... reação de setores do Estado refratários à ampliação da participação social no ambiente acadêmico, ... o Pronera sofreu reação a essa forma de gestão colegiada e coletiva, notadamente à participação direta dos movimentos sociais e sindicais do campo" (Santos, 2012, p. 634).

Ressalta-se que, nos anos 2000, os movimentos sociais e sindicais já vinham reestruturando os seus fundamentos e agendas de lutas, como abordado neste texto. No âmbito macro, já se encontravam fragmentados pela perda da consciência de "classe para além de si"; as suas lutas haviam se particularizado e, consequentemente, a sua capacidade de barganha e ação junto ao Estado encontrava-se enfraquecida. As ações decorrentes daí demonstram o grande poder de força e persuasão tanto da face política quanto da face civil do Estado para afastar a participação popular do poder de gestão do Pronera.

Inicialmente, o Acórdão TCU $\mathrm{n}^{\mathrm{o}}$ 2.653/2008 (Brasil, 2008) determinou que os movimentos sociais não poderiam mais participar de qualquer fase de escolha da entidade prestadora de ensino para projetos do Pronera, negando a participação popular, uma das premissas da Lei de Diretrizes e Bases da Educação (Brasil, 1996).

Tal decisão foi ratificada pelo Decreto $\mathrm{n}^{\mathrm{o}}$. 7.352/2010, que cita os movimentos sociais apenas no art. $2^{\mathrm{o}}$ : "são princípios da educação do campo ... V controle social da qualidade da educação escolar, mediante a efetiva participação da comunidade e dos movimentos sociais do campo", sem definir como se daria tal participação. A esses movimentos, que tinham conquistado um espaço significativo de ação e poder dentro do Pronera, coube, a partir de então, o papel de assistentes, já que foram considerados como "entes estranhos à administração pública" pelo TCU, no Acórdão $\mathrm{n}^{\mathrm{o}}$ 2.653/2008 (Brasil, 2008). 
Essa alteração foi oficializada, também, nas orientações do Manual de Operações do Pronera de 2012 (Brasil, 2012) que, mesmo mantendo os movimentos sociais e sindicais como parceiros do Programa, limitaram a sua participação. São parceiros do Programa: "as instituições de ensino, pesquisa e extensão, públicas e privadas sem fins lucrativos e fundações de apoio; as secretarias municipais e estaduais de educação; e os movimentos sociais e sindicais representativos do público beneficiário", entendidos como

... organizações de trabalhadores rurais, representativas dos beneficiários, em âmbito local, estadual e nacional. [Com as atribuições de]: indicar as demandas educacionais das áreas de reforma agrária e do crédito fundiário, em conjunto com os demais parceiros; acompanhar e avaliar o processo pedagógico dos cursos (Brasil, 2012, p. 23).

A atualização do Manual de Operações do Pronera, em 2016, manteve essas atribuições e incluiu uma nova aos movimentos sociais e sindicais: “... efetuar o controle social, entendido este como a 'participação do cidadão na gestão pública, na fiscalização, no monitoramento e no controle das ações da Administração pública"” (Brasil, 2016a, p. 27). ${ }^{v}$
Portanto, seguindo as determinações jurídicas, a legislação e as orientações do Pronera pós-2008 (Acórdão n 2.653/08), 2010 (Decreto $\mathrm{n}^{\circ}$ 7.352/2010) e 2012 (Manual de Operações) suprimiram o poder de participação dos movimentos sociais e sindicais na tomada de decisões nas áreas administrativa e financeira, restringindo seu campo de atuação à identificação de demanda e a poucos aspectos pedagógicos dos projetos.

Outra interferência do Poder Judiciário no Pronera ocorreu em 2010, por meio do Acórdão TCU 3.269/10, determinando que, mesmo se tratando de um Programa, na sua gênese, destinado a um grupo específico, os povos do Campo e da reforma agrária, na sua organização:

...1) não pode haver restrição à participação de alunos que não pertençam a determinado movimento social; 2) não pode haver inserção nos projetos educacionais de disciplinas curriculares ou extracurriculares que visem à formação de técnicos militantes ou a concessão de privilégios indevidos a movimentos sociais ou entidades afins; 3) não pode haver provisão de indicadores de resultados qualitativos dos cursos, tendo por base o acompanhamento político, pedagógico, técnico e social por parte dos movimentos sociais; 4) não pode haver previsão de avaliações dos discentes com base em seu comprometimento com os movimentos sociais; 5) deverá constar dos instrumentos de contratação, exigência de que a instituição, ao selecionar professores 
destinados a ministrar aulas do curso, realize processo seletivo simplificado com ampla divulgação e concorrência, pautando-se por critérios objetivos e transparentes e pelos princípios básicos da administração pública, mormente, os da impessoalidade e moralidade, impedindo que questões políticas, partidárias, filosóficas ou ideológicas influenciem a escolha do corpo docente (Brasil, 2012, p. 19).

Mais uma vez, o Estado, por meio do TCU, instituiu meios regulatórios para o afastamento dos movimentos sociais e sindicais do Programa. Com essa alteração no corpo constitutivo do Pronera, aos poucos, outras mudanças foram se fazendo, de modo que o Incra assumiu a centralidade administrativa, financeira e também pedagógica do Programa, por meio da ampliação do papel da Coordenação Geral das Políticas de Formação de Professores do Campo. Assim, secundarizou-se ainda mais o papel do MEC, mantendo uma política de educação apenas sob a coordenação do MDA e com "apoio técnico e financeiro" do Ministério da Educação (art. $4^{\circ}$ e $9^{\circ}$ ) (Brasil, 2010).

Ao MEC coube, a partir do Decreto $\mathrm{n}^{\mathrm{o}}$. 7.352/2010 (Brasil, 2010), o papel de coadjuvante que pode "art. $10 \ldots$ realizar parcerias com outros órgãos e entidades da administração pública para o desenvolvimento de ações conjuntas, e para apoiar programas e outras iniciativas no interesse da educação do campo observadas as diretrizes fixadas neste Decreto".

Esse Decreto (Brasil, 2010) evidencia, também, a tendência de desresponsabilização do Estado com a educação, em especial no que tange ao financiamento, ao estabelecer, no parágrafo único, do art. $3^{\circ}$ que, ao desenvolverem a Educação do Campo, em regime de colaboração com a União, estados, Distrito Federal e municípios deverão “... criar e implementar mecanismos que garantam sua manutenção e seu desenvolvimento nas respectivas esferas, de acordo com o disposto neste Decreto".

A análise dessas rupturas e reorganizações em torno do Pronera evidencia a estruturação de mecanismos regulatórios do Estado, para controle dos povos do Campo e dos movimentos sociais e sindicais. À medida que centraliza a gestão, coibindo a gestão colegiada e coletiva, por meio da participação direta dos movimentos, o Incra apodera-se do controle das decisões e dos rumos da Educação do Campo, podendo produzir estratégias que satisfaçam aos interesses e à lógica do sistema do capital, por meio da educação formal dos sujeitos do Campo e da reforma agrária. 
Ao mesmo tempo em que ascende ao atendimento dos povos do Campo e da reforma agrária, o Pronera vai catalisando ao Incra o poder de gestão da Educação do Campo. O atual Manual de Operações do Programa (Brasil, 2016a), ao manter tais perspectivas, aponta que o processo continua em curso.

\section{Estrutura Pronera: a centralidade da} gestão da Educação do Campo ao Incra
Em 2001, antes das decisões impetradas pelos Acórdãos 3.253/2008 (Brasil, 2008) e 3.269/10 (Brasil, 2012), pelo Decreto nº. 7.352/2010 (Brasil, 2010), e revisões ideológicas e estruturais do Manual de Operação do Programa (Brasil, 2001; 2004; 2012; 2016a), o Pronera era composto, nos âmbitos nacional e estadual, por representantes de todos os segmentos que participaram da sua criação (Figura 1):

Figura 1. Organização da Gestão do Pronera - 2001.

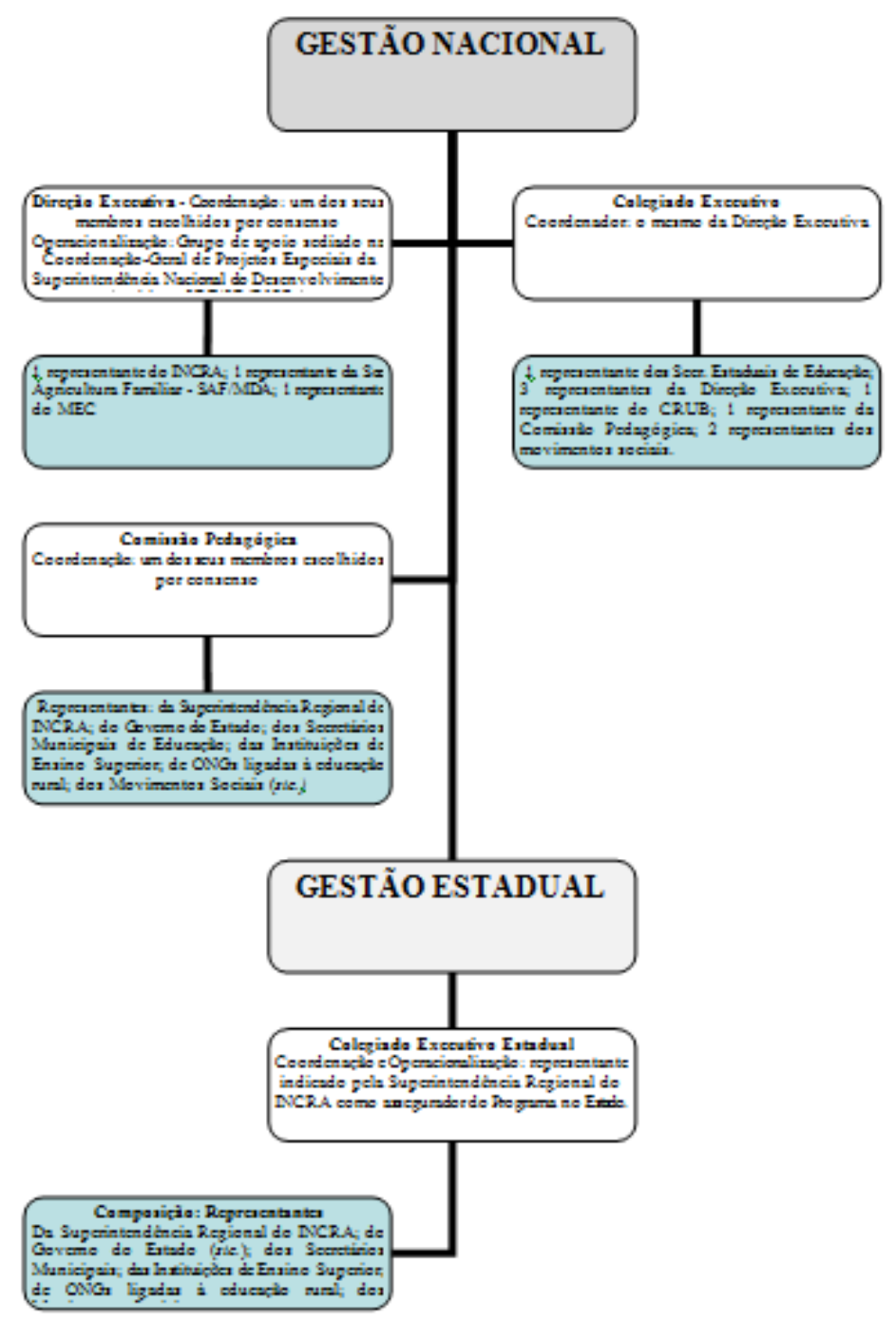

Fonte: Manual de Operações (Brasil, 2001). 
Ao longo dos seus 18 anos de existência, como afirmado neste texto, a estrutura organizacional, a delimitação dos papéis dos parceiros e a gestão do Programa foram sendo adulteradas, e o seu contorno inicial, pouco a pouco, ganhou uma arquitetura diferente da original, desenhada em 2001.
A estrutura organizacional do Pronera, em 2016, passou a compor-se por duas instâncias (Figura 2) reafirmando a centralidade do Incra no comando geral dos projetos e restringindo a participação dos parceiros ao âmbito da gestão estadual.

Figura 2. Organização da Gestão do Pronera - 2016.

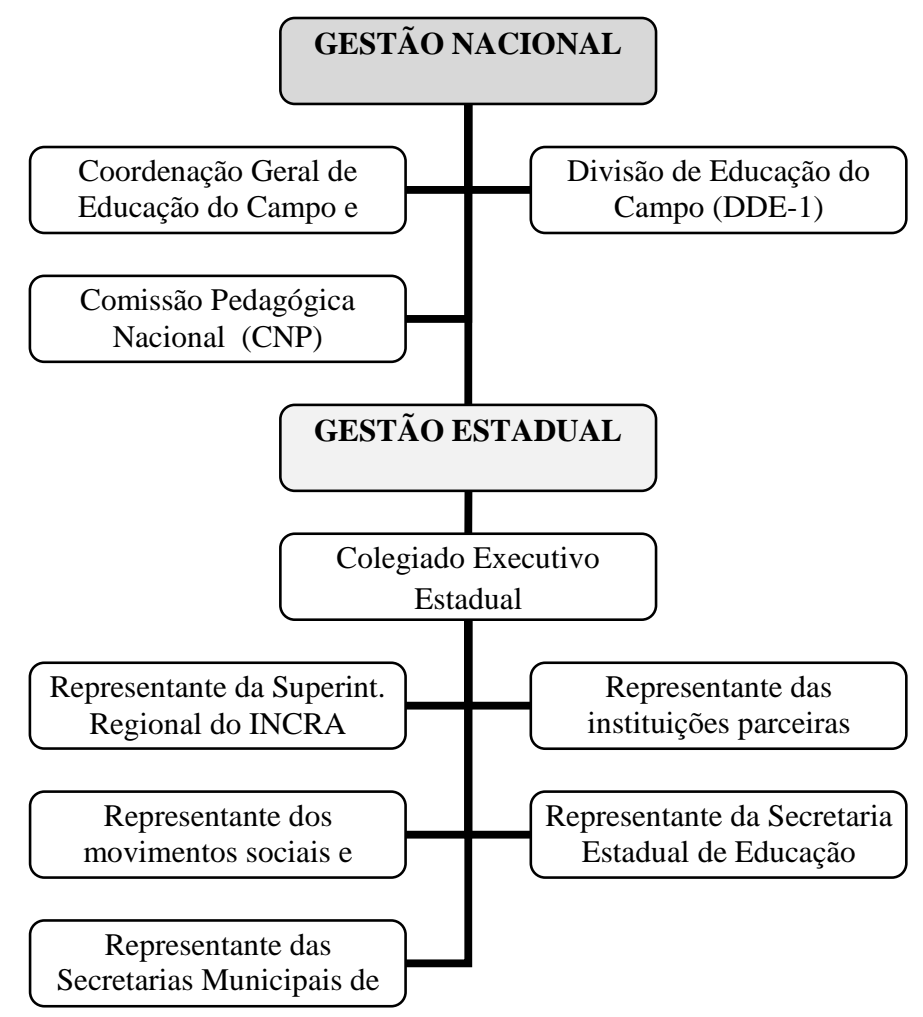

Fonte: Manual de Operações (Brasil, 2016a).

Por outro lado, as atribuições da Coordenação Geral de Educação do Campo e Cidadania (DDE) - cuja coordenação geral cabe ao Coordenador Nacional do Pronera - abarcam a tomada de decisões sobre todos os aspectos do
Programa e não apontam o trabalho de interlocução com os parceiros em nível nacional:

... coordenar, supervisionar e propor atos normativos, manuais $\mathrm{e}$ procedimentos técnicos para as atividades relacionadas à educação 
do campo e cidadania; definir a gestão política e pedagógica do Programa Nacional da Educação na Reforma Agrária - Pronera; promover a articulação interministerial e dos poderes públicos para integração do Pronera e das ações de cidadania; coordenar a Comissão Pedagógica Nacional; apoiar a produção de material didático, pedagógico e científico no âmbito da educação e coordenar as ações voltadas para o exercício da cidadania pelos beneficiários da reforma agrária (Brasil, 2016a, p. 22).

Esse também é o preceito que rege as ações da Divisão de Educação do Campo (DDE); contudo, há uma referência aos parceiros, mas exclui os movimentos sociais e sindicais de participação nessa instância:

... promover acesso à educação formal em todos os níveis, de alfabetização, ensino básico, formação profissional de nível médio, superior e pós-graduação para o público beneficiário, por meio de contratos, convênios, termos de cooperação e instrumentos congêneres, para a execução das ações do Pronera; propor atos normativos, planejar, implementar, acompanhar e avaliar os projetos referentes à educação na reforma agrária; promover ações articuladas com o conjunto das políticas públicas para a educação; promover parcerias no âmbito dos governos federal, estaduais e municipais, instituições públicas de ensino e instituições privadas de ensino sem fins lucrativos; articular a interação dos cursos executados no âmbito do Pronera, ou outro que vier a substituílo, com as ações do Programa de Assessoria Técnica, Social e
Ambiental - ATES; analisar e emitir parecer técnico sobre as propostas de parceria no âmbito do Pronera; supervisionar, monitorar e avaliar as atividades pedagógicas desenvolvidas nos Estados, juntamente com as Superintendências Regionais do Incra; apoiar e orientar os colegiados executivos estaduais; articular estudos e pesquisas referentes à educação nas áreas de reforma agrária; fomentar a criação de bibliotecas nas áreas de reforma agrária; apoiar a produção de material didático e pedagógico que discuta e apresente proposta para a erradicação do trabalho escravo; apoiar os estudos para a produção de material didático e pedagógico no âmbito da educação na reforma agrária; propor critérios $\mathrm{e}$ metodologias visando ao controle, uso, manutenção, segurança, atualização e disseminação de dados para o sistema de informação, de modo a garantir que sejam contemplados as diretrizes e os procedimentos previstos nos atos normativos de sua competência; e outras atividades compatíveis com suas atribuições (Brasil, 2016a, p. 2223).

Ainda no âmbito nacional, a Comissão Pedagógica Nacional desenvolve atividades de assessoria e consultoria, coordenada pelo titular da DDE, sendo uma

... instância responsável pela orientação e definição das ações político-pedagógicas do Programa. Será composta por representantes de instituições de ensino, Ministério do Desenvolvimento Agrário, Ministério da Educação, os movimentos sociais e sindicais na condição de representantes da sociedade civil e Incra (Brasil, 2016a, p. 24). 
Mesmo vinculando sua coordenação ao DDE, esta Comissão, de função consultiva, é a única instância de participação dos movimentos sociais e sindicais, no Pronera, em nível nacional, cujas atribuições são

... orientar e definir as ações políticopedagógicas do Pronera; identificar, discutir, desenvolver e avaliar metodologias e instrumentos pedagógicos pertinentes aos pressupostos teórico-metodológicos do Programa; apoiar e orientar os colegiados executivos estaduais; emitir parecer técnico/pedagógico sobre propostas de trabalho e/ou projetos; acompanhar e avaliar, em conjunto com as Superintendências Regionais do INCRA, as ações do programa nos estados e nas regiões; articular, em conjunto com as Superintendências Regionais do INCRA, os governos estaduais e municipais, as instituições de ensino públicas e privadas sem fins lucrativos para promoverem a ampliação e implementação das ações do Programa nos estados e regiões; participar, a convite do INCRA, de eventos para apresentação e representação do Programa (Brasil, 2016a, p. 24).

No âmbito estadual, o Pronera está sob a gestão de um Colegiado Executivo Estadual, capitaneado pelo Incra, com as atribuições de

... divulgar, coordenar, articular, implementar, acompanhar e avaliar o programa em âmbito estadual; mobilizar, dinamizar e orientar as atividades de alfabetização, escolarização em nível fundamental e médio, formação técnico-profissional de nível médio e de nível superior junto às instituições de ensino públicas e/ou privadas sem fins lucrativos; promover parcerias no âmbito dos governos federal, estadual e municipal; e das instituições de ensino públicas e/ou privadas sem fins lucrativos; avaliar as atividades pedagógicas desenvolvidas no estado (Brasil, 2016a, p. 25).

Como se pode ler, são ações executivas periféricas do Programa aquelas que incluem uma participação mais efetiva dos parceiros e do MEC, possibilitando o total controle do Pronera pelo Incra.

O Pronera, na época da sua criação, elegeu como um dos principais critérios para um projeto ser aprovado, quanto ao mérito, o de ter sido elaborado coletivamente, envolvendo a instituição pública que o desenvolveria, superintendências regionais do Incra e movimentos sociais e sindicais de trabalhadores a serem atendidos (Brasil, 2004). Contudo, a reformulação do Programa, a partir da sua transformação em política de Estado (Decreto $\mathrm{n}^{\circ}$ 7.352/2010) e expressa no atual Manual de Operações do Pronera, exclui esse critério (Brasil, 2016a).

Aliás, as parcerias que se estabeleceram para o Pronera, nesses 18 anos de existência, sempre foram marcadas por contradições internas e externas, dadas as correlações de força entre as classes 
sociais e a existência de antagonismos (Antônio \& Martins, 2009; Freitas, 2008).

Em um estudo sobre o tema, Freitas (2008) conclui que são diversas as questões que recrudescem as relações de parceria no âmbito do Pronera, permeadas por posições político-ideológicas, destacando-se: diferença de olhares entre os movimentos sociais e as universidades sobre a realidade e as ações dos assentados; conflito entre urgências e demandas; leituras diversas sobre a natureza do trabalho educativo; distância entre a lógica e a cultura universitária e a dos movimentos sociais; dificuldade da universidade em compartilhar responsabilidades e decisões com os movimentos sociais; imposição ideológica dos movimentos sociais aos demais parceiros; a forma artesanal com a qual o Incra assume a Educação do Campo, etc.

A centralidade da gestão do Pronera assumida pelo Incra, ao longo desses anos, parece objetivar o abrandamento de tais dissensos, antagonismos e conflitos, como se tal determinação pudesse diluir a essência política, social e educacional da sociedade, e, em especial, dos povos do Campo.

\section{Considerações finais}

O discurso presente no primeiro Manual de Operações do Pronera, em
2001, foi composto a partir dos princípios da Educação Popular, de uma educação libertadora, emancipadora dos sujeitos do Campo e da reforma agrária, em parceria com os movimentos sociais e, posteriormente, os sindicais. Entretanto, no decorrer dos 18 anos de existência do Programa, tais preceitos foram substituídos pela centralização de poder nas mãos do Incra, colaborando para que o projeto de educação e de sociedade que moveu os sujeitos em 1997, durante o I Enera, a criarem um programa de educação popular, com forte caráter de justiça e transformação social, se transformasse em instrumento de manutenção e funcionamento da sociedade segundo a ordem do sistema do capital.

Após o ano de 2008, princípios organizacionais passaram a representar a reestruturação do Pronera para adequá-lo ao modelo hegemônico de sociedade do capital, mesmo que alguns dos seus princípios e pressupostos mantenham o discurso da educação como direito, para emancipação dos povos da reforma agrária e do Campo.

Por outro lado, a transposição da responsabilidade pela gestão Educação do Campo do MEC para o MDA/Incra, por meio do Pronera, traz implicações de caráter político, social, educacional e econômico, apontando para um 
esvaziamento da missão do MEC, em relação à educação pública.

Um Instituto, criado para implementar a política de reforma agrária e realizar o ordenamento fundiário nacional, ao assumir a centralidade na gestão das questões educacionais do Campo, aponta para a abertura de um caminho para que esse processo de esvaziamento da missão do MEC se consolide.

Em tempos de orientação neoliberal para as políticas públicas, em especial para as sociais, é preciso colocar em foco essas discussões para que a corporeidade da educação brasileira, organizada no âmbito do MEC, não se esvaia em políticas desconcentradas e redistribuídas nos demais Ministérios do governo. Tal mecanismo acabaria por romper os avanços já alcançados para a constituição de um sistema nacional de educação no país, revestindo-a de contorno e conteúdo focalizador-assistencialista e fragilizando-a enquanto direito subjetivo do cidadão brasileiro.

\section{Referências}

Adorno, T. W., \& Horkheimer, M. (2006). Dialética do esclarecimento: fragmentos filosóficos. Rio de Janeiro, RJ: Editora Jorge Zahar.

Aith, F. (2006). Políticas públicas de Estado e de governo: instrumentos de consolidação do Estado Democrático de
Direito e de promoção e proteção dos direitos humanos. In Bucci, M. P. D. (Org.). Políticas públicas - reflexões sobre o conceito jurídico (p. 217-245). São Paulo, SP: Saraiva.

Antonio, C. A., \& Martins, F. J. (2009). Estado, educação e movimentos sociais do campo: luta social pela educação do campo no Brasil. Revista Caderno de Pesquisa: pensamento educacional, 4(8), 42-63.

Arroyo, M. G. (2007). Políticas de formação de educadores(as) do campo. Cadernos do Cedes. Centro de Estudos Educação e Sociedade. Educação do campo, 27(72), 157-176.

Brasil. (1970). Decreto-lei $n^{\circ} 1.110$ de 9 de julho de 1970. Cria o Instituto Nacional de Colonização e Reforma Agrária (Incra). Diário Oficial da União, Brasília, DF, 10 jul. 1970.

Brasil. (1996). Lei n. 9394 de 20 de dezembro de 1996. Estabelece as diretrizes e bases da educação. Diário Oficial da União, Brasília, DF, 21 dez. 1996.

Brasil. (1998). Portaria $n^{o} 10$ de 16 de abril de 1998. Cria o Programa Nacional de Educação na Reforma Agrária Pronera, vinculando ao Gabinete do Ministro e aprova o seu Manual de Operações. Diário Oficial da União, Brasília, DF, 17 abr. 1996.

Brasil. (2001). Ministério do Desenvolvimento Agrário. Instituto Nacional de Colonização e Reforma Agrária. Programa Nacional de Educação na Reforma Agrária. Manual de Operações do Pronera. Brasília, DF: MDA/INCRA/PNERA.

Brasil. (2004). Ministério do Desenvolvimento Agrário. Instituto Nacional de Colonização e Reforma Agrária. Programa Nacional de Educação 
na Reforma Agrária. Manual de Operações do Pronera. Brasília, DF: MDA/INCRA/PNERA.

Brasil. (2008). Tribunal de Contas da União. Acórdão n. 2.653/08. Diário Oficial da União, Brasília, DF, ago., 2008.

Brasil. (2009a). Decreto n. 6.812/2009 de 3 de abril de 2009. Aprova a Estrutura Regimental e o Regimento Interno do Incra. Diário Oficial da União, Brasília, DF, 4 abr. 2009.

Brasil. (2009b). Portaria n. 20 de 8 de abril de 2009. Aprova o Regimento Interno do Incra. Diário Oficial da União, Brasília, DF, 21 abr. 2009.

Brasil. (2010). Decreto $n^{o} 7.352 / 2010$ de 4 de novembro de 2010. Dispõe sobre a política de educação do campo e o Programa Nacional de Educação na Reforma Agrária - Pronera. Diário Oficial da União, Brasília, DF, 5 nov. 2010.

Brasil. (2012). Ministério do Desenvolvimento Agrário. Instituto Nacional de Colonização e Reforma Agrária. Programa Nacional de Educação na Reforma Agrária. Manual de Operações do Pronera. Brasília, DF: MDA/INCRA/PNERA.

Brasil. (2015). Portaria n. 563 de 23 de outubro de 2015. Estabelece o valor máximo financiável por aluno/ano, na modalidade de Alfabetização e Escolarização (Ensino Fundamental - $1^{\mathrm{a}}$ a $4^{\mathrm{a}}$ série), Ação: Educação de Jovens e Adultos - EJA. Diário Oficial da União, Brasília, DF, 24 out. 2015.

Brasil. (2016a). Ministério do Desenvolvimento Agrário. Instituto Nacional de Colonização e Reforma Agrária. Programa Nacional de Educação na Reforma Agrária. Manual de Operações do Pronera. Brasília, DF: MDA/INCRA/PNERA.

Brasil. (2016b). Pronera: Educação na Reforma Agrária. Recuperado de: http://www.incra.gov.br/educacao_pronera

Brasil. (2017). Portaria n. 49 de 31 de janeiro de 2017. Aprova o Regimento Interno do Incra. Diário Oficial da União, Brasília, DF, 1 fev. 2017.

Freitas, H. C. A. (2008). A formação da rede de educação de assentados da reforma agrária: o Pronera. Trabalho não publicado.

Gramsci, A. (2011). Cadernos do cárcere. Maquiavel. Notas sobre o Estado $e$ a política. Rio de Janeiro, RG: Editora Civilização Brasileira.

IPEA. (2015). II PNERA. Relatório da II Pesquisa Nacional sobre a Educação na Reforma Agrária. Recuperado de: http://www.incra.gov.br/sites/default/files/ uploads/reforma-agraria/projetos-eprogramas/pronera/pnera-2pesquisa-educareforma-agraria.pdf

Marx, K. (2008). Contribuição à crítica da economia política. São Paulo, SP: Editora Expressão Popular.

Mendes, M. J. (2015). A Despesa Federal em Educação: 2004-2014. Brasília, DF: Núcleo de Estudos e Pesquisas/CONLEG/Senado, abril/2015 (Boletim Legislativo $\mathrm{n}^{\circ}$ 26, de 2015). Recuperado de: https://www.senado.leg.br/estudos

Mészáros, I. (2011). Para além do capital. Rumo a uma teoria da transição. São Paulo, SP: Boitempo Editorial. 
Portal Brasil. (2010). Aluno universitário custa cinco vezes mais que um estudante da educação básica. (2010, 16 de março). Recuperado de: http://www.brasil.gov.br/educacao/2010/03 /aluno-universitario-custa-cinco-vezesmais-que-um-estudante-da-educacao$\underline{\text { basica }}$

Santos, C. (2010, 23 de dezembro). Entrevista. Pronera: os desafios e avanços para a educação do campo. Recuperado de: http://boletimmstrj.mst.org.br/pronera-osdesafios-e-avancos-para-a-educacao-docampo/

Santos, C. (2012). Programa Nacional de Educação na Reforma Agrária (Pronera). In: Caldart, R.S. et al. (Org.). Dicionário de Educação do Campo (p. 629-637). Rio de Janeiro, RJ: Escola Politécnica de Saúde Joaquim Venâncio/Expressão Popular.

Filho, S. R., B., \& Araújo, R. M. L. (2017). Evasão e abandono escolar na educação básica no Brasil: fatores, causas e possíveis consequências. Educação por Escrito, 8(1), $35-48$.

\footnotetext{
i Já há uma parcela significativa dos que vivem, pensam e estudam os movimentos sociais que defendem a incursão adjetiva de "novíssimos" movimentos sociais, de caráter global, em rede.
}

ii Há quem defenda essa fragmentação dos movimentos como uma estratégia própria para se adequarem às novas imposições e barreiras postas pelo sistema do capital. Nós, ao contrário, percebemos que essa estratégia tem origem nos mecanismos contra-regulatórios do próprio sistema do capital, gerenciados pelo Estado.

iii O Pronacampo visa ampliar o acesso e a qualificação da oferta da educação básica e superior, por meio de ações de infraestrutura, a formação inicial e continuada de professores, a produção e a oferta de material didático. iv O Programa objetiva fomentar ações inovadoras para troca de saberes entre as comunidades populares e a universidade, incluindo jovens oriundos das comunidades do campo, quilombola, indígena e em situação de vulnerabilidade social.

v De acordo com o documento "Controle Social: orientações aos cidadãos para participação na gestão pública e exercício do controle social/2012", da Controladoria Geral da União (CGU).

Recebido em: 24/07/2017 Aprovado em: 28/08/2017 Publicado em: 11/08/2017

Como citar este artigo / How to cite this article / Como citar este artículo:

APA:

Lélis, U. A., Silva, M. V., \& Gomes, M. A. A. S. (2017). Políticas públicas de gestão da Educação do Campo no contexto de reestruturação organizacional do Pronera. Rev. Bras. Educ. Camp., 2(2), 650-676. DOI: $\quad$ http://dx.doi.org/10.20873/uft.25254863.2017v2n2p650

ABNT:

LÉLIS, U. A., SILVA, M. V.; GOMES, M. A. A. S. Políticas públicas de gestão da Educação do Campo no contexto de reestruturação organizacional do Pronera. Rev. Bras. Educ. Camp., Tocantinópolis, v. 2, n. 2, p. 650-676, 2017. DOI: http://dx.doi.org/10.20873/uft.25254863.2017v2n2p650

\section{ORCID}

Úrsula Adelaide de Lélis

http://orcid.org/0000-0002-4683-4444

Maria Vieira Silva

http://orcid.org/0000-0002-9369-0930

Maria Auxiliadora Amaral Silveira Gomes

http://orcid.org/0000-0002-2028-0420 